\title{
El principio de legalidad en el Derecho Penal Internacional The principle of legality in International Criminal Law
}

\author{
Rodrigo Lledó \\ Universidad Carlos III de Madrid \\ rodrigolledo@hotmail.com
}

Recibido / received: 12/09/2016

Aceptado / accepted: 16/09/2016

DOI: http://dx.doi.org/10.20318/eunomia.2016.3291

\begin{abstract}
Resumen
Partiendo de la constatación de que en el derecho internacional no existen leyes, en un sentido similar al derecho interno, y que por tanto en ese ámbito no puede regir un principio de legalidad con el mismo significado y contenido (nullum crimen sine lege), el presente trabajo pretende dar cuenta de cuál ha sido la comprensión de este principio en el ámbito internacional, donde ha sido más bien definido como un principio de juridicidad (nullum crimen sine iure), que sin embargo de todas formas aspira a cumplir con el estándar internacional en cuanto derecho humano y principio básico de justicia, incluso de la justicia penal internacional.
\end{abstract}

\section{Palabras Clave}

Derecho penal, derecho internacional, derecho penal internacional, principio de legalidad, Corte Penal Internacional, Tribunal Europeo de Derechos Humanos.

\begin{abstract}
Based on the finding that international law has no Acts, in the similar sense as domestic law has, and therefore, in this area cannot apply the principle of legality with the same meaning and content (nullum crimen sine lege), this paper seeks to explain what has been the understanding of this principle in the international arena, where it has been more clearly defined as a principle of jurisdicity (nullum crimen sine iure), yet anyway aims to meet the international standard as a human right and a basic principle of justice, even international criminal justice.
\end{abstract}

\section{Key Words}

Criminal law, international law, international criminal law, principle of legality, International Criminal Court, European Court of Human Rights.

SUMARIO. 1. Introducción. 2. El principio de legalidad penal en el ámbito internacional. 3. El contenido del principio de legalidad en el derecho internacional. 4. Del nullum crimen sine lege al nullum crimen 
sine iure. 5. 5. Fuentes del derecho penal internacional. 6. El principio nulla poena sine lege. 7. Conclusiones.

\section{Introducción}

Ya existe en esta revista una voz referida al principio de legalidad penal (Lamarca, 2011). A ella, pues, nos remitimos en cuanto al significado y comprensión de este principio, uno de los pilares fundamentales del derecho penal moderno (Quintero Olivares, 2010: 48; Muñoz Conde y García Arán: 86), en los países de tradición de derecho codificado ${ }^{1}$.

¿Cómo se ha entendido tan importante principio penal en el ámbito internacional? Desde luego, la primera y más elemental constatación es que en el derecho internacional no existen leyes, tal y como las conocemos en el ámbito interno, por lo que este trabajo bien podría concluir aquí, señalando con justa razón, que el nullum crimen sine $\operatorname{lege}^{2}$ no rige en el derecho penal internacional ${ }^{3}$.

Sin embargo, el principio de legalidad no sólo es un principio elemental de la justicia penal ${ }^{4}$, sino que también se ha transformado en un derecho humano, siendo recogido por las principales convenciones internacionales y regionales de derechos humanos $^{5}$, así como por prácticamente todas las legislaciones del mundo ${ }^{6}$, existiendo un verdadero derecho a la legalidad penal (nombre tomado de Huerta Tocildo, 1993: 81-113).

De este modo, si bien en el derecho internacional no existen leyes propiamente tales, y no puede, por tanto, existir en propiedad un principio de legalidad en idénticos términos al que rige en el derecho penal interno, de alguna manera debe reconocerse la aplicación de los elementos esenciales de este principio, a fin de poder cumplir con un estándar de justicia con pleno respeto a los derechos fundamentales del imputado, incluso del imputado por un delito internacional. Contribuir a precisar cuál es ese estándar, es el objetivo del presente trabajo ${ }^{7}$.

\footnotetext{
${ }^{1}$ En oposición al llamado derecho anglosajón o common law.

${ }^{2}$ Como es sabido, se atribuye a Feuerbach, a mediados del siglo XIX, la formula latina nulla poena sine lege, nulla poena sine crimine, nullum crimen sine poena legali, o más brevemente nullum crimen sine lege. Aun cuando debe advertirse que Feuerbach no utilizó literalmente la expresión nullum crimen sine lege, sino las otras tres ya mencionadas (Mir Puig, 2008: 105, nota 2).

3 Hay quien estima que la Corte Penal Internacional infringe el principio nullum crimen sine lege, y opina además que todos los esfuerzos por crear una justicia supranacional están cruzados por la ideología de la punición infinita, no siendo más que "una suerte de «represalia individual», aunque lo llamemos derecho penal internacional" (Pastor, 2006: 68, 75 y ss., 85).

${ }^{4}$ Anticipándose a las críticas, la sentencia del Tribunal de Núremberg señaló que: "la máxima nullum crimen sine lege no es una limitación de la soberanía sino, en general, un principio de justicia." (Tribunal de Núremberg, 1946, citado en Gallant, 2012: 315).

${ }^{5}$ Tras el juicio de Núremberg el principio de legalidad penal fue recogido en la Declaración Universal de los Derechos Humanos de 1948 (art. 11.2), dos años más tarde en el Convenio Europeo de Derecho Humanos de 1950 (art. 7) y tiempo después en el Pacto Internacional de Derechos Civiles y Políticos de 1966 (art. 15), en la Convención Americana de Derechos Humanos de 1969 (art.9), en la Carta Africana sobre los Derechos Humanos y de los Pueblos de 1981 (art. 7.2), y más recientemente en la Carta de Derechos Fundamentales de la Unión Europea del año 2000, y su versión revisada del año 2007 (art. 49), así como la Carta Árabe de los Derechos Humanos, de 2004 (art. 15).

${ }^{6}$ Todos los Estados pertenecientes a la Organización de las Naciones Unidas, excepto Bután y Brunei, han adoptado el principio de legalidad, ya sea en sus constituciones, ya sea en sus normas legislativas o por medio de su vinculación a tratados internacionales de derechos humanos (Olásolo, 2013: 24)

7 Trabajo que es la síntesis de un trabajo mayor, que es la tesis doctoral del mismo autor de este artículo, de febrero de 2016, por la Universidad Carlos III de Madrid, dirigida por la catedrática de derecho penal Dra. Da. Carmen LAMARCA PÉREZ.
} 


\section{El principio de legalidad penal en el ámbito internacional}

El primer antecedente del principio en la esfera internacional lo constituye una Opinión Consultiva de la Corte Permanente de Justicia Internacional, de 1935, en el caso Danzing (Ferdinandusse, 2006: 222$)^{8}$, en el cual la Corte debió Juzgar si el nuevo Código Penal de la Ciudad Libre de Danzing, que preveía expresamente la aplicación de la analogía ${ }^{9}$, se ajustaba a la Constitución vigente. Si bien la Corte no fijó con precisión cuál debía ser el contenido del principio de legalidad, estableció como criterio general mínimo que: "debe ser posible para el individuo conocer, de antemano, si sus actos son legales o susceptibles de ser castigados" (Corte Permanente de Justicia Internacional, 1935: 57).

El principio de legalidad penal también ocupó un destacado lugar en los debates que tuvieron lugar durante el transcurso de la Segunda Guerra, como también antes y durante del juicio de Núremberg y los demás juicios locales llevados adelante por los Aliados ${ }^{10}$. Son de sobra conocidas las diversas críticas que recibió el Tribunal de Núremberg una vez concluida su labor, las que pueden fácilmente reconducirse a dos, que son, el haber sido una justicia de los vencedores sobre los vencidos, al no haber sido verdaderamente llevada a cabo por un tribunal imparcial con un auténtico carácter internacional; y no haber respetado el principio de legalidad, especialmente lo que dice relación con la irretroactividad penal (Jiménez de Asúa, 1950: 1283) ${ }^{11}$.

Tras el juicio de Núremberg, el principio de legalidad penal fue recogido en la Declaración Universal de los Derechos Humanos de 1948, que prohíbe con toda claridad la aplicación retroactiva de los delitos y de las penas, señalando que la conducta ha debido ser delictiva con anterioridad a la comisión del hecho, según el "derecho" nacional o internacional ${ }^{12}$. Como se puede apreciar, la Declaración y las convenciones posteriores hablan de "derecho" nacional e internacional, sin hacer

\footnotetext{
${ }^{8}$ El artículo $1^{\circ}$ del nuevo Código decía: "Any person who commits an act which the law declares to be punishable or which is deserving of penalty according to the fundamental conceptions of a penal law and sound popular feeling, shall be punished. If there is no penal law directly covering an act, it shall be punished under the law of which the fundamental conception applies most nearly to the said act." El representante de la ciudad de Danzing sostenía que lo que se pretendía era reemplazar una justicia formal por una justicia real, y que la máxima nullum crimen sine lege nulla poena sine lege, en adelante y desde esta nueva perspectiva, debía ser reformulada como nullum crimen sine poena.

${ }^{9}$ Según el art. $1^{\circ}$ del Código Penal de 1930: "Sólo cae bajo la ley el acto cuyo carácter punible está previsto por la legislación danesa o una acción enteramente asimilable a ese acto" (citado en Cerezo Mir, 2004: 201, nota 68).

${ }^{10} \mathrm{Si}$ bien Kelsen reconocía que varias constituciones prohibían las leyes retroactivas y que el principio de legalidad penal era reconocido por la mayoría de las naciones civilizadas, sostenía que se trataba de derecho interno y no de derecho internacional, por lo que justificaba la aplicación retroactiva de los delitos, por tratarse de un tribunal internacional. Kelsen señalaba: "No hay regla de derecho internacional general consuetudinario que prohíba la promulgación de normas con fuerza retroactiva, las llamadas leyes ex post facto" (Kelsen, 2008: 103). Resulta interesante apuntar aquí que, Carl Schmitt escribió un informe en derecho en 1945 para un hombre de negocios que iba a ser juzgado por su supuesta responsabilidad en la colaboración financiera de los crímenes nacionalsocialistas. Muchos años más tarde este informe fue publicado por un profesor de derecho penal con sus comentarios (véase Schmitt, 2006). En este trabajo Schmitt recuerda algunas normas y sucesos que tuvieron lugar bajo el régimen Nazi y que, según la concepción occidental, infringían el principio de legalidad penal. Para Schmitt, sin entrar a valorar lo que denomina "innovaciones legales del régimen nacionalsocialista", destaca que la irritación que ellas causaron en la opinión pública "demuestra que la proposición «nullum crimen sine lege» es universalmente reconocida", por lo que sería raro que ahora se desconociera la validez del principio. No obstante, advierte de las extraordinarias diferencias de la praxis continental europea, inglesa y estadounidense (Schmitt, 2006: 34-36).

${ }_{11}^{1}$ Amplias referencias a las opiniones expresadas por juristas de la época en las páginas siguientes.

${ }^{12}$ Así lo recoge la Declaración Universal (art. 11.2), y también el PIDCP (art. 15), el Convenio Europeo (art. 7) y la Carta de Derechos Fundamentales de la Unión Europea (art. 49.1). Por su parte la Convención Americana habla de "derecho aplicable" (art. 9) y la Carta Africana de "ofensa legalmente punible" (art. 7.2).
} 
referencia a la "ley" o a alguna otra fuente del derecho (nacional o internacional). En general, se tiende a pensar que ello se debe a la necesidad de compatibilizar los distintos sistemas jurídicos, particularmente el sistema de derecho continental codificado y el sistema anglosajón o common law ${ }^{13}$. No obstante, los travaux préparatoires de la Declaración Universal dan cuenta de que, contrariamente a lo que pudiera pensarse, no fueron las diferencias entre sistemas jurídicos las que influyeron de manera determinante en la redacción actual de la disposición ${ }^{14}$, sino que fue nuevamente el fantasma del juicio de Núremberg, a través de la llamada "enmienda belga" ${ }^{15}$, cuyo propósito declarado fue prevenir la posibilidad de que en el futuro los historiadores alemanes usaran la redacción original del artículo para tratar de demostrar la ilegalidad de los juicios sobre crímenes de guerra, especialmente los de Núremberg ${ }^{16}$. La enmienda no fue aprobada, pero en cambio se modificó el texto haciéndolo más general, al hacer referencia al "derecho" nacional e internacional ${ }^{17}$.

La fallida "enmienda belga" en la Declaración Universal es de un tenor muy similar, cuando no idéntico, al que poco tiempo más tarde sería propuesto, esta vez con éxito, en el Convenio Europeo de Derechos Humanos (art. 7.2) ${ }^{18}$ y en el Pacto

${ }^{13}$ En este sentido, Cerezo nos recuerda que "[e]n Inglaterra no se llevó a cabo el proceso de codificación y no triunfó, por tanto, el principio de legalidad, frutos ambos del racionalismo del Continente europeo, de corte Francés" (2004: 200). Por su parte, Jiménez de Asúa (1964: 390), nos recuerda que en dicho sistema el juez poseía además un "cierto poder autónomo de represión".

${ }_{14}$ Varios Estados formularon distintas propuestas de una disposición referida al principio de legalidad, todas las cuales hacían referencia a una "ley vigente" o en vigor al momento de la comisión del delito (Schabas, 2013). Se consignan las propuestas de Cuba, de 12 febrero de 1946: "laws in force prior to the act"; Panamá, de 26 de abril de 1946: "a law in effect at the time of the commission of the act; Chile, en representación del Comité Jurídico Interamericano: "the law in force at the time the act was committed" (ver Schabas, 2013: 533); también una propuesta posterior de Francia, de 16 de junio de 1947: "some law in effect at the time of the act" (ver Schabas, 2013: 791). Incluso la propuesta de Estados Unidos, país de common law, disponía "a law in effect at the time of the commission of the act" (ver Schabas, 2013: 714 - 715). La única excepción fue la propuesta presentada por el Reino Unido, que era del siguiente tenor: "No person shall be held guilty of any offence on account of acts or omissions which did not constitute such_an offence at the time when they were committed." (ver Schabas, 2013: 295 [cursiva propia]). En el borrador del Comité de Redacción para una carta internacional de derechos humanos, de 11 de junio de 1947, disponía en su artículo 26: "No one shall be convicted of crime except by judgment of a court of law for violation of a law in effect at the time of the commission of the act charged as an offence, nor be subjected to a penalty greater than that applicable at the time of the commission of the offence." (Cfr. Schabas, 2013: 532 [cursiva propia]). Un segundo borrador, de 1 julio de 1947, disponía en lo pertinente, ahora en el artículo 10: "No one can be convicted of crime unless he has violated some law in effect at the time of the act charged as an offence nor be subjected to a penalty greater than that applicable at the time of the commission of the offence. No one, even if convicted for a crime, can be subjected to torture." (ver Schabas, 2013: 932 [cursiva propia]). Un tercer borrador es el de la Cuarta Reunión del Grupo de Trabajo sobre la Declaración de Derechos Humanos, de 8 de diciembre de 1947, que también en el artículo 10, en lo pertinente disponía: "Any person is presumed innocent until proved guilty. No one shall be convicted or punished for a crime or another offence except after fair public trial at which he has been given all guarantees necessary for his defence and which shall be pursuant to law in effect at the time of the commission of the act charged. No one shall be subjected to torture or to cruel or inhuman punishment or indignity". (Schabas, 2013: 1245 [cursiva propia]).

15 "This provision shall not, however, preclude the trial and conviction of persons who have committed acts which, at the time of their commission, were regarded as criminal by virtue of the general principles of law recognized by civilized nations." (Schabas, 2013: 1268). La propuesta es de 12 de diciembre de 1947.

${ }^{16}$ Según consta en el Acta resumen de la 36ª reunión de la Comisión Derechos Humanos, de fecha 13 de diciembre de 1947 (Schabas, 2013: 1268 y ss.; la afirmación del representante belga se encuentra en Schabas, 2013: 1275).

${ }^{17}$ Fue precisamente el Reino Unido y la India los Estados que propusieron, el 24 de mayo de 1948, suprimir la "enmienda belga" en la Declaración Universal, reformulándose el artículo para dejar expresa constancia de que los delitos podían ser establecidos tanto por el "derecho nacional" como por el "derecho internacional" (Schabas, 2013: 1619 y ss.).

${ }^{18}$ Los trabajos preparatorios del Convenio Europeo se encuentran disponibles en formato electrónico (Trabajos preparatorios del Convenio Europeo de Derechos Humanos). Cabe hacer notar que durante un tiempo varios documentos tuvieron un carácter confidencial, como es el caso de los 
Internacional de Derechos Civiles y Políticos (art. 15.2) ${ }^{19}$, que declaran expresamente que el principio de legalidad no impide el juzgamiento de hechos que son delictivos de acuerdo a los principios generales de derecho reconocidos por las naciones civilizadas, o por la comunidad internacional, respectivamente. Por su parte, la Convención Americana recurre a una fórmula todavía más genérica de "derecho aplicable", al tiempo que incorpora perentoriamente la retroactividad de la ley posterior más favorable (art. 9$)^{20}$.

\section{El contenido del principio de legalidad en el derecho internacional}

Las convenciones internacionales sólo recogen explícitamente la irretroactividad ${ }^{21}$, y genéricamente la irretroactividad del "derecho", tanto nacional como internacional. Por ello, debemos acudir a la jurisprudencia para poder conocer en concreto cuál es el estándar establecido, para luego intentar determinar si éste cumple con los parámetros de nuestro tradicional principio de legalidad penal, en cuanto a lege scripta, stricta, certa y praevia ${ }^{22}$.

La concepción del principio de legalidad de la Corte Interamericana (Corte IDH) se inserta de lleno en la tradición de derecho codificado, lo que es consistente con el sistema jurídico seguido por los países latinoamericanos ${ }^{23}$, reconociendo expresamente y con el mismo lenguaje, la exigencia de taxatividad o lex certa (Corte IDH, Caso Castillo Petruzzi y otros Vs. Perú, 1999: párr. 121; Caso Lori Berenson Mejía Vs. Perú, 2004: párr. 125) y de la irretroactividad o lex praevia

correspondientes al artículo 7 del Convenio que aquí nos ocupa, que hoy se han desclasificado y se encuentran disponibles en dos informes compilatorios de 1957 y 1970, que hoy se encuentran disponibles (vid. Preparatory work on article 7 of the European Convention of Human Rights, 1957; 1970).

19 Para mayores detalles sobre los trabajos preparatorios sobre el Pacto Internacional, ver Gallant (2009: 178 y ss.).

${ }^{20}$ Por su parte, la Declaración Americana de Derechos Humanos, de 1948, no recoge el principio de legalidad penal de manera separada, sino que aparece inserto dentro de la protección de otros derechos, pero siempre haciendo referencia a "leyes" preexistentes. Así, el artículo XXV que versa sobre el Derecho de protección contra la detención arbitraria, consigna en el inciso primero que: "Nadie puede ser privado de su libertad sino en los casos y según las formas establecidas por leyes preexistentes. En el artículo siguiente, sobre el "Derecho a proceso regular", tras consagrar el principio de presunción de inocencia, se dispone que: "Toda persona acusada de delito tiene derecho a ser oída en forma imparcial y pública, a ser juzgada por tribunales anteriormente establecidos de acuerdo con leyes preexistentes y a que no se le imponga penas crueles, infamantes o inusitadas".

${ }^{21}$ Lo propio acontece en el derecho interno donde, por lo general, las constituciones políticas son en general más bien escuetas y no consagran expresamente todos los elementos del principio de legalidad, los cuales, no obstante, la doctrina y la jurisprudencia se encargan de derivar del texto positivo. La Constitución Española en el artículo 25.1 sólo recoge de manera explícita la irretroactividad de las leyes penales, y ha sido la doctrina y la jurisprudencia la que ha deducido de éste y otros artículos de la Constitución los demás elementos del principio. Así por ejemplo, la irretroactividad de la pena, se deriva de las menciones genéricas al sometimiento de la ley de los artículos 9 y 117.1 de la Constitución (ver Muñoz Conde y García Arán, 2010: 99).

${ }^{22}$ Tradicionalmente los elementos materiales del principio de legalidad penal son tres, lex scripta, lex praevia y lex stricta, pero cada vez son más quienes para mayor claridad, dividen este último elemento en dos materias diferenciadas, abordando de manera separada, como un cuarto elemento, la lex certa. Así lo hacen entre otros Muñoz Conde, con la salvedad hecha previamente en la nota anterior, y en Alemania Jakobs (1997: 79) y Hassemer (1995: 21-22).

${ }^{23}$ Para mayores aspectos referidos al artículo 9 de la Convención Americana de Derechos Humanos, ver: Espejo Yaksic y Leiva García (2012: 399-408). Igualmente, puede consultarse a Olásolo (2013: 31 y ss.), quien advierte que la protección que ofrece la accesibilidad y la previsibilidad puede ser incluso más amplia y favorable al individuo que las rígidas disposiciones de lex scripta, stricta, certa y praevia. Lo formula de la siguiente manera: "Es por ello que una aplicación formal de los requisitos lex praevia, lex scripta, lex certa y lex stricta en este tipo de casos, en lugar del juicio de conocimiento de la antijuridicidad material exigido por los requisitos de accesibilidad y previsibilidad, lleva a un resultado contrario al exigido por el principio pro homine, en relación con el ámbito de aplicación del Derecho al recurso judicial efectivo de aquellos que, encontrándose en situación de vulnerabilidad, han sufrido la violencia sistemática o generalizada de quienes han actuado bajo el amparo directo o indirecto de las instituciones públicas." (2013: 35). 
(Corte IDH, Caso Baena Ricardo y otros Vs. Panamá, 2001: párr. 107; Caso Ricardo Canese Vs. Paraguay, 2004: párr. 177; Caso Lori Berenson Mejía Vs. Perú, 2004: párr. 125; Caso Castillo Petruzzi y otros Vs. Perú, 1999: párr. 121).

Ha sido el Tribunal Europeo de Derechos Humanos (en adelante TEDH), el que ha tenido que efectuar una conceptualización del principio de legalidad, que pueda ser aplicable tanto en el sistema de derecho codificado como en el sistema anglosajón, habiéndose pronunciado además sobre qué se ha de entender por "derecho" nacional e internacional, así como sobre el inciso segundo, referido a los principios generales de derecho reconocidos por las naciones civilizadas.

En cuanto al concepto de "derecho", el TEDH ha señalado que "comprende tanto el derecho escrito como el no escrito, lo que implica exigencias cualitativas, que incluyen las de accesibilidad y previsibilidad" (TEDH, Caso S.W. contra el Reino Unido, 1995b: pár. 35; Caso C.R. contra el Reino Unido, 1995c: pár. 33; Caso Streletz, Kessler y Krenz contra Alemania, 2001a, pár. 50; Caso K.-H.W contra Alemania, 2001b: pár. 45; Caso Korbely contra Hungría, 2008: pár. 70; Caso Kononov contra Letonia, 2010: pár. 185; Caso Vyerentsov contra Ukraine, 2013a, pár. 63; Caso Maktouf y Damjanović contra Bosnia y Herzegovina, 2013b: pár. 66, entre otros $)^{24}$. En otras ocasiones, no obstante, el TEDH ha matizado, dejando de lado las controvertidas expresiones "derecho escrito" y "derecho no escrito", señalando en cambio que el concepto de "derecho" comprende tanto a la "ley" en sentido formal (statutory law), como a la "jurisprudencia" (case law) e implica exigencias cualitativas, que incluyen las de accesibilidad y previsibilidad" (TEDH, Caso Cantoni contra Francia, 1996: párr. 29; Caso Başkaya y Okçouglu contra Turquía, 1999: pár. 36; Caso Coëme y otros contra Bélgica, 2000: pár. 145; Caso E. K. contra Turquía, 2002a: pár. 51; Caso Achour contra Francia, 2006: pár. 42; Caso Jorgic contra Alemania, 2007: pár. 100; Caso Scoppola contra Italia ( $\left.n^{\circ 2}\right)$, 2009: pár. 99 , entre otros $)^{25}$.

La doctrina suele destacar que a partir dos casos, S.W. (1995b) y el caso C.R. (1995c), ambos contra el Reino Unido, se ha desarrollado una jurisprudencia bastante arraigada en el TEDH (Sarmiento, Mieres y Presno, 2007: 60), que admite el llamado derecho "no escrito". Sin embargo, existen otras muchas sentencias en las que ya no se utiliza la dicotomía "derecho escrito" y "derecho no escrito", sino "ley en sentido formal" (statutory law) y "jurisprudencia" (case law).

En todas las sentencias del TEDH sobre el art. 7 , se hace mención a las exigencias cualitativas de accesibilidad y previsibilidad, teniendo ocasión además de precisarlas en reiterada jurisprudencia.

En cuanto al requisito de la accesibilidad, la doctrina ha destacado que "no ha generado grandes problemas a lo largo de la jurisprudencia, pues alude a una elemental y sencilla exigencia de publicidad de las normas" (Sarmiento, Mieres y Presno, 2007: 60). De hecho, esta exigencia se superpone, en parte, con la previsibilidad, ya que, si lo que dispone la norma penal debe ser previsible para el ciudadano, lógicamente primero debe poder tener acceso a ella, para lo cual ha de estar públicamente disponible (Harris, O’Boyle, Warbrick et al., 2009: 334, nota al pie 32; véase también TEDH, Caso G. contra Francia, 1995a).

\footnotetext{
${ }^{24}$ El texto original en inglés señala: "When speaking of 'law', Article 7 alludes to the same concept as that to which the Convention refers elsewhere when using that term, a concept which comprises written and unwritten law and which implies qualitative requirements, notably those of accessibility and foreseeability".

${ }^{25}$ El texto original en inglés señala: "When speaking of 'law' Article 7 alludes to the very same concept as that to which the Convention refers elsewhere when using that term, a concept which comprises statutory law as well as case-law and implies qualitative requirements, notably those of accessibility and foreseeability".
} 
Sobre la previsibilidad el TEDH ha señalado algunos criterios para determinar cuándo se cumple con este requisito y cuándo no, tales como el contenido del texto del que se trata, el ámbito que cubre, así como del número y de la calidad de los destinatarios. También ha dicho que la previsibilidad de la ley no se opone a que la persona implicada tenga que recurrir a asesores para evaluar, hasta un grado razonable según las circunstancias del caso, las consecuencias que pudieran resultar de un acto determinado, como ocurre con los profesionales, habituados a ser prudentes en su trabajo, pudiendo esperarse de ellos que pongan un cuidado especial en evaluar los riesgos que supone su conducta (TEDH, Caso Cantoni contra Francia, 1996; Sarmiento, Mieres y Presno, 2007: 61).

La doctrina ha intentado conceptualizar este requisito de la previsibilidad, a la luz de los criterios que proporciona el TEDH, despertando ciertas dudas por parte algunos autores, atendida su flexibilidad o falta de concreción, no estando suficientemente claro si se trata de un concepto objetivo (en el cual la previsibilidad se evaluaría en relación con el común de los ciudadanos), o bien de un concepto subjetivo (en el cual la previsibilidad se evaluaría en relación con el ciudadano concreto $)^{26}$. Hay quien piensa que la previsibilidad "es un estándar de conducta que requiere de un particular conocimiento, o una práctica, de las condiciones que le son jurídicamente exigibles", y que varía dependiendo de si es o no un profesional o carente de formación (Sarmiento, Mieres y Presno, 2007: 61), como ha expresado el TEDH en el Caso Cantoni contra Francia (1996). También se ha considerado que lo que interesa al TEDH es la previsibilidad "jurídica" y no la fáctica, que es indiferente a los efectos del principio de legalidad penal (De Vicente Martínez, 2004: 191), como lo demostrarían los casos Streletz, Kessler y Krenz contra Alemania (TEDH, 2001a: párr. 50) y K.-H.W contra Alemania (TEDH, 2001b: párr. 45).

Ambas conceptualizaciones, en mi opinión, parecen ser complementarias y no contradictorias. Por una parte el TEDH, según su propia jurisprudencia, habrá de considerar las circunstancias personales y fácticas del caso concreto, pero, por otra parte, a partir de estas circunstancias, valorándolas, deberá construir un estándar de lo que es "razonablemente" exigible en términos de previsibilidad, esto es, un estándar normativo o jurídico. En efecto, y yendo al ejemplo antes citado, muy probablemente la posibilidad concreta de un juicio y una posterior condena no estuvo presente en la mente de los centinelas del Muro de Berlín al momento de los hechos, atendida una "práctica estatal" que justificaba e incluso alentaba tales conductas. Sin embargo, desde un punto de vista jurídico, el enjuiciamiento y la condena eran perfectamente plausibles al ser las conductas contrarias tanto al derecho de la RDA como al derecho internacional, siendo, en consecuencia, jurídicamente previsibles.

Lo que sí podemos descartar por completo, en mi opinión, es que la previsibilidad sea un concepto puramente subjetivo, que evalúe el conocimiento real y efectivo del acusado. En la jurisprudencia del TEDH, recordemos, hay dos conceptos, la previsibilidad y la accesibilidad, que son complementarios y de hecho se superponen, como hemos dicho. La accesibilidad, aunque se solape con la previsibilidad, cobra sentido propio e independiente precisamente aquí. Basta con que la disposición penal haya estado públicamente disponible, que haya sido accesible, para que podamos luego evaluar la previsibilidad dependiendo del contenido de la norma en cuestión. Si el ciudadano no quiere conocer la disposición, no quiere acceder a ella, pudiendo razonablemente hacerlo, la norma le será

\footnotetext{
${ }^{26}$ Huerta reconoce que la previsibilidad persogue dar cierto grado de seguridad jurídica, pero critica que este concepto no haya sido objeto de "excesivas concreciones" (Huerta Tocildo, 2009: 518).
} 
igualmente exigible. Considerados ambos criterios conjuntamente, podemos concluir que, en la jurisprudencia del TEDH, la previsibilidad y la accesibilidad no son criterios subjetivos, sino criterios objetivos a la vez que jurídicos, digamos, criterios de carácter objetivo-normativo.

Sin duda, los conceptos de previsibilidad y accesibilidad persiguen el valor de la seguridad jurídica, esto es, que el ciudadano sepa de antemano "a qué atenerse" ${ }^{\prime 27}$, para lo cual el ciudadano debe poder conocer qué conductas lo harán responsable penalmente. Ello, tanto desde el propio texto, por sí mismo, como con la ayuda de asesoría jurídica, si fuere necesario, como hemos visto.

Ahora bien, desde una perspectiva crítica, hay quien considera que estas exigencias cualitativas de accesibilidad y previsibilidad estarían, aparentemente, destinadas a "compensar" la ausencia de reserva de ley formal en el Convenio y la jurisprudencia del TEDH (Huerta Tocildo, 2009: 518). Sin embargo, en mi opinión, en cuanto accesibilidad y previsibilidad son exigencias cualitativas, ellas tienen relación, no tanto con la jerarquía de fuentes de la norma penal, como con los demás elementos del principio de legalidad. En efecto, en cuanto al mandato de taxatividad o lex certa, la previsibilidad opera como una directriz hacia el legislador en cuanto a la necesaria claridad que debe tener un texto normativo. En cuanto a lex stricta o prohibición de analogía e interpretaciones extensivas, el TEDH reconoce que, "por muy bien redactado que esté un texto normativo, siempre es necesario interpretarlo, lo que es válido para toda rama del ordenamiento jurídico, incluido el derecho penal", ya que siembre habrá necesidad de aclarar puntos dudosos, como también de adaptar la norma a nuevas circunstancias, lo que es más intenso en algunos Estados, en los que el desarrollo progresivo del derecho penal se ha dado por vía jurisprudencial, de acuerdo a su tradición jurídica (así está dicho en los siguientes casos: TEDH, Caso Streletz, Kessler y Krenz contra Alemania, 2001a: pár. 50; Caso K.-H.W contra Alemania, 2001b: pár. 45; Caso Jorgic contra Alemania, 2007, pár. 100; Caso Korbely contra Hungría, 2008, pár. 70). EI TEDH añade, en este mismo sentido, que el artículo 7 "no puede ser interpretado como una prohibición de la clarificación gradual de las normas de responsabilidad penal a través de la interpretación judicial caso a caso, siempre que el resultado de este desarrollo sea consistente con la esencia del delito y pueda ser razonablemente previsible" (TEDH, Caso Streletz, Kessler y Krenz contra Alemania, 2001a: pár. 50; Caso K.-H.W contra Alemania, 2001b: pár. 45; Caso Jorgic contra Alemania, 2007, pár. 100; Caso Korbely contra Hungría, 2008, pár. 70).

Si esto es así, ello implica que no sólo el texto legal ha de ser previsible, sino también las interpretaciones jurisprudenciales, lo que nos lleva el problema de la irretroactividad penal o lex praevia, tanto de la ley como de la jurisprudencia, tema, este último, debatido en el derecho interno, aunque resuelto recientemente por el TEDH en el caso Del Río Prada contra España (TEDH, Caso Del Río Prada contra España, 2012: pár. 48).

La previsibilidad y la accesibilidad, entonces, son los criterios que el TEDH emplea para evaluar lo que en derecho interno conocemos como los elementos materiales del principio de legalidad de lex stricta, certa y praevia.

Con respecto al artículo 7.2, el TEDH ha tenido ocasión de pronunciarse en pocas ocasiones, y lo ha hecho sobre todo en algunas decisiones de admisibilidad y

\footnotetext{
${ }^{27}$ Esta es la expresión empleada por Diez-Picazo (2008: 471) para graficar cuál es en esencia la exigencia de taxatividad de la ley penal, ya que si bien la claridad, precisión y determinación absoluta es inalcanzable, existe un mínimo que "resulta constitucionalmente indisponible".
} 
sentencias (véase la sistematización efectuada en: Casadevall, 2012: 323). Aquí, la pregunta relevante que ha planteado la doctrina es si estamos frente una excepción al principio de legalidad. Notablemente, la mayoría de los autores consultados consideran que el artículo 7.2 es una excepción a la regla general contenida en el artículo $7.1^{28}$, de modo tal que -en concepto de estos autores- existiría un grupo de situaciones que estarían excluidas o exceptuadas de la aplicación del principio de legalidad penal en la forma establecida en el Convenio, lo que, incluso, ha llegado a ser considerado como una excepción a la inderogabilidad del principio de legalidad establecida en el artículo 15 del mismo Convenio ${ }^{29}$.

Sin embargo, la jurisprudencia más reciente del TEDH contradice esta común opinión. En el caso Maktouf y Damjanović contra Bosnia y Herzegovina (TEDH, 2013b), luego de resolver la discusión principal del caso que giraba en torno a cuál de los dos códigos disponía la pena más favorable, el TEDH no pudo dejar de rebatir los argumentos esgrimidos por el gobierno, según el cual los hechos (crímenes de guerra cometidos en el contexto del conflicto de la antigua Yugoslavia) eran delictivos de acuerdo con "los principios generales reconocidos por las naciones civilizadas", previsto en el artículo 7.2, por lo que -decía el gobierno- no se aplicaba la prohibición de retroactividad de los delitos y las penas. EI TEDH señaló que este argumento del gobierno era inconsistente con los travaux préparatoires, según los cuales el artículo 7.1 puede ser considerado como una regla general de prohibición de la retroactividad, y el artículo 7.2 es sólo una clarificación contextual de la obligación contenida en ella, que fue incluido con el fin de asegurar que no existiera ninguna duda sobre la validez de los juicios posteriores a la Segunda Guerra Mundial, con respecto a los crímenes cometidos durante esa guerra (en este mismo sentido, TEDH, Caso Kononov contra Letonia, 2010: párr. 186). Es claro -añade el TEDH- que los redactores del Convenio no intentaron autorizar ninguna excepción general a la prohibición de retroactividad. EI TEDH recordó que ha sostenido en varias ocasiones que ambos párrafos del artículo 7 están interconectados y deben ser interpretados de una manera concordante (TEDH, Caso Maktouf y Damjanović contra Bosnia y Herzegovina, 2013b, párr. $\left.72^{30}\right)$.

\section{Del nullum crimen sine lege al nullum crimen sine iure}

Pues bien, es precisamente este estándar del TEDH el que ha sido aplicado por el Tribunal para la ex Yugoslavia (Nilsson, 2007: 58 y ss.) y Ruanda (Trahan, 2010: 142 y ss.). La Corte Penal Internacional contempla expresamente el principio de legalidad penal en su Estatuto $^{31}$, define detalladamente los crímenes de su

\footnotetext{
${ }^{28}$ En Van Dijk et al. (2006: 660) se titula el acápite pertinente como "La excepción al párrafo segundo"; Huerta Tocildo (2009: 519 y ss.) también titula el párrafo como "Excepciones al principio de irretroactividad de las normas penales desfavorables"; Harris et al. (2009: 338) "Principios generales de la Derecho de excepción"; y Casadevall (2012: 322) titula "La excepción del párrafo 2", en el cual afirma que "[e]l párrafo segundo del artículo 7 contiene una excepción o derogación de las garantías contenidas en el párrafo primero".

${ }^{29}$ Van Dijk (2006: 662) afirma: "Como se puede observar, sin embargo, la consecuencia de este párrafo segundo del artículo 7 que, con respecto a ciertos delitos esta garantía no es absoluta, ni en las situaciones referidas en el artículo 15.1 ni en otros casos".

${ }^{30}$ Cita el TEDH el caso Tess contra Letonia (dec.), $N^{\circ} 34854 / 02,12$ de diciembre de 2002, además del ya citado caso Kononov.

31 Cuyo artículo 22 establece lo siguiente: "Nullum crimen sine lege. 1. Nadie será penalmente responsable de conformidad con el presente Estatuto a menos que la conducta de que se trate constituya, en el momento en que tiene lugar, un crimen de la competencia de la Corte. 2. La definición de crimen será interpretada estrictamente y no se hará extensiva por analogía. En caso de ambigüedad, será interpretada en favor de la persona objeto de investigación, enjuiciamiento o condena. 3. Nada de lo dispuesto en el presente artículo afectará a la tipificación de una conducta como crimen de derecho internacional independientemente del presente Estatuto".
} 
competencia, tanto en el Estatuto como en los llamados "Elementos de Crímenes". Ello no fue casual, sino que fue el fruto de un intenso trabajo académico, denominado más tarde "Proyecto Siracusa", en el cual participaron, entre otras organizaciones, la Asociación Internacional de Derecho Penal (AIDP) y el Instituto Max Plank de Derecho Penal Extranjero e Internacional de Friburgo (Werle, 2005: 69 , nota al pie 112). Este proyecto contenía un total de 21 artículos que sintetizaban las principales instituciones de la parte general del derecho penal, muchas de las cuales influyeron en el trabajo de la Comisión Preparatoria (Ambos, 1996: 521).

Desde que en el ámbito internacional no hay leyes, ni Estado, ni Estado de Derecho ni democracia propiamente tal, hay quien opina que todos estos esfuerzos son indeseables (Pastor, 2006: 99 y ss.). Pero, poniendo la mirada en quienes han intentado construir un derecho penal internacional, pese a las dificultades teóricas y prácticas, hay que tomar en consideración varios factores, entre otros, las distintas tradiciones jurídicas.

Así como en el derecho anglosajón es difícil hablar de un principio de legalidad, ya que no todo el derecho penal está basado en la ley desde que coexisten los Statutory offences con los tradicionales y antiguos common law offences, siendo reconducido a un "principio de juridicidad"; del mismo modo, en el derecho penal internacional los autores han reformulado el principio de forma semejante, llamándolo algunos nullum crimen sine iure (Ollé Sesé, 2008: 582), o bien nullum crimen sine lege (Ferdinandusse, 2006: 232; Remiro Brotons, 1999: 5960 ), pero concibiendo a la lex en un sentido amplio, como sinónimo de Derecho.

Cherif Bassiouni lo explica tomando en cuenta "la ausencia de un órgano legislativo internacional", por lo que plantea que "el principio de legalidad del derecho penal internacional puede ser mejor expresado por la máxima "nullum crimen sine iure", la que es "algo menos restrictiva que las rígidas aproximaciones nacionales positivistas de nullum crimen sine lege, que connota una mucho mayor especificidad". Para Bassiouni, "nullum crimen sine iure" incluye prohibiciones legales que surgen tanto del derecho convencional como consuetudinario, los cuales declaran que ciertas conductas son prohibibles o punibles (1996: 268; también en Hormazabal Malarée, 2013: 253-280).

En definitiva, el nullum crimen sine iure no prejuzga ni impone un sistema de fuentes. Lo que se exige es que la conducta sea constitutiva de delito, conforme al sistema de fuentes previsto para la creación del Derecho Penal, ya sea en el ordenamiento jurídico nacional de que se trate o en el ordenamiento internacional (Olásolo, 2013: 27).

Aun cuando el principio nullum crimen sine iure es indudablemente más flexible que el principio de legalidad en la formulación tradicional del sistema de derecho codificado, de todas formas está limitado por ciertos principios fundamentales, como la irretroactividad de todo derecho aplicable, la cual está sólidamente incrustada en el derecho penal internacional (Cassese, 2008: 44), y los requisitos de accesibilidad y previsibilidad, que son aplicados en la práctica internacional. Ante ello, hay quien estima que la reformulación del nullum crimen sine iure "no altera el núcleo del principio", en el sentido en que la norma ha de ser previa, con lo que de todas formas hay una barrera a la arbitrariedad, aun cuando la norma esté contenida en un convenio internacional, establecida en la costumbre o en los principios generales de derecho (Hormazabal Malarée, 2013: 256-257).

Ahora bien, en la definición de los delitos se constata que en el proceso de formación de las normas que los contienen ha estado exenta de una política y una 
técnica consistente de redacción (Cherif Bassiouni, 1996: 288). Como resultado, muchas de ellas contienen definiciones amplias de los delitos, lo que proporciona mayor libertad al juez y al mismo tiempo representa un problema en términos de lex certa.

Este problema se ve agravado porque, bajo el principio nullum crimen sine iure, no sólo se incluye la aplicación de los delitos internacionales establecidos en convenciones, sino también aquellos que emanan del derecho consuetudinario.

Se hace así necesario que revisemos cuáles son las fuentes del derecho penal internacional que formarían parte de este iure del principio nullum crimen sine iure, que a partir de ahora denominaremos principio de legalidad internacional.

5. Fuentes del derecho penal internacional

La condición de híbrido jurídico del derecho penal internacional se manifiesta con fuerza aquí, a la hora de determinar cuáles son las fuentes de este derecho, y particularmente desde cuáles de las fuentes formales pueden emanar los delitos internacionales y su penalidad, ante la ausencia de leyes en sentido estricto.

Se reconoce en general que las fuentes del derecho internacional general son las establecidas en el artículo 38 del Estatuto de la Corte Internacional de Justicia, que incluye: los tratados internacionales, la costumbre, los principios generales y, como secundarias o auxiliares, la jurisprudencia y la doctrina científica. Pero estas fuentes fueron establecidas para un Tribunal internacional que no posee competencia penal, ya que está encargado exclusivamente de resolver los problemas que se suscitan entre los Estados. Sin embargo, en general, se plantea este mismo sistema de fuentes para el derecho penal internacional (Olásolo, 2013: 27; así también Hormazabal Malarée, 2013: 256).

Mientras, en general, es bastante aceptado que se establezcan delitos internacionales mediante un tratado internacional, como es el caso del Genocidio o los Crímenes de Guerra, la polémica surge a la hora de considerar si un delito puede emanar de lo que se ha llamado el "derecho no escrito", como la costumbre y, todavía más, los principios generales.

Observemos brevemente la evolución del derecho penal internacional, desde perspectiva de las fuentes formales que han establecido los delitos internacionales. El problema no se planteó mayormente en los juicios de Núremberg y Tokio, toda vez que los Tribunales aplicaron exclusivamente el respectivo Estatuto, retroactivamente, con las consabidas críticas a las que ya nos hemos referido. En relación con los tribunales para Ruanda y la ex Yugoslavia, sus respectivos Estatutos definen los delitos en términos amplios, por lo que deben recurrir a fuentes que están más allá de lo expresamente contenido en ellos. En este sentido, los Estatutos sólo efectúan una referencia genérica al derecho internacional humanitario en cuanto derecho aplicable. Fue el redactor del Estatuto del Tribunal para la ex Yugoslavia, el Secretario General, quien propuso que el Tribunal debería aplicar normas que fueran, más allá de toda duda, derecho internacional consuetudinario. Pero además, el Secretario General identificó ese derecho internacional consuetudinario en fuentes precisas, a saber: las cuatro Convenciones de Ginebra de 1949; el IV Convenio de La Haya sobre las leyes y costumbres de la guerra terrestre y su reglamento anexo, de 1907; la Convención para la Prevención y Sanción del Delito de Genocidio de 1948; y el Estatuto del Tribunal Militar Internacional de Núremberg de 1945 (Report of the Secretary-General Pursuant to paragraph 2 of Security Council Resolution 808, 1993: párr. 35). 
Notemos que se acaba de identificar el derecho internacional consuetudinario aplicable e inmediatamente aparecen varias convenciones internacionales. ¿Cómo es posible esto?

En el derecho internacional general está bastante asentado que una misma norma puede existir como tratado y a la vez constituir una costumbre internacional (Mariño Menéndez, 2005: 442). En lo que respecta al derecho penal internacional, la situación no es diferente. Alicia Gil Gil (1999: 84) y Manuel Ollé Sesé (2008: 562), basados en la "interacción de las distintas fuentes del derecho internacional", sostienen también que una norma jurídica internacional puede tener simultáneamente el carácter de un tratado internacional y a la vez ser una costumbre internacional y/o un principio general.

De este modo, la Convención contra el Genocidio, si bien nace originalmente como un tratado internacional vinculante únicamente para los Estados parte, en la actualidad forma parte del ius cogens, por lo que es vinculante para todos los Estados como una norma de derecho consuetudinario, sean o no parte de esta Convención. Otro tanto es posible decir con respecto a las Convenciones de Ginebra de 1949, y también al Estatuto y las sentencias del Tribunal de Núremberg aprobadas como "Principios" por la Asamblea General de Naciones Unidas. Los crímenes internacionales, llamados por Ollé Sesé crímenes internacionales de primer grado (2008: 575), tienen para ambos autores el carácter de ius cogens (Gil Gil, 1999: 89; Ollé Sesé, 2008: 575).

Ahora bien, las dudas pueden persistir en cuanto a los principios, pero puede afirmarse que el nullum crimen sine iure los incluye como una fuente sustantiva de criminalidad, atendido lo dispuesto en los art. 7 (2) del Convenio Europeo ${ }^{32}$ y del art. 15 (2) del Pacto Internacional ${ }^{33}$. Al respecto, Kai Ambos puntualiza que los principios generales de derecho internacional del Pacto Internacional y la Convención Europea no deben entenderse en el mismo sentido del artículo 38 del Estatuto de la Corte Internacional de Justicia, sino que se trata de una referencia a las reglas, también consuetudinarias, desarrolladas a partir del derecho de Núremberg (2006: 36), esto es, los Principios de Núremberg, que más que principios en el sentido tradicional, serían reglas consuetudinarias. En efecto, así lo demostraría el hecho de que el Secretario General de Naciones Unidas haya identificado el Estatuto del Tribunal de Núremberg, más allá de toda duda, como parte del derecho internacional consuetudinario aplicable por el Tribunal para la ex Yugoslavia.

De este modo, podemos convenir en que, independientemente de que los crímenes internacionales que son objeto del derecho penal internacional, que son los crímenes de guerra, contra la humanidad, el genocidio y el crimen de agresión, ellos tienen existencia internacional en calidad de norma ius cogens, y pueden ser invocados como Principios (Estatuto y Principios de Núremberg), como tratado o convención (Convención contra el Genocidio, Convenciones de Ginebra de 1949 y de La Haya de 1907), y además como derecho internacional consuetudinario.

Es por ello que es posible sostener, además, que en general estos crímenes satisfacen los estándares de accesibilidad y previsibilidad, girando las dudas y discusiones no en cuanto a la retroactividad o la inexistencia de fuentes, sino más

\footnotetext{
${ }^{32}$ Que establece lo siguiente: "El presente artículo no impedirá el juicio o la condena de una persona culpable de una acción o de una omisión que, en el momento de su comisión, constituía delito según los principios generales del derecho reconocidos por las naciones civilizadas".

${ }^{33}$ Que dispone que "nada de lo dispuesto en este artículo se opondrá al juicio ni a la condena de una persona por actos u omisiones que, en el momento de cometerse, fueran delictivos según los principios generales del derecho reconocidos por la comunidad internacional".
} 
bien en cuanto a los términos amplios en que los delitos están definidos en todos esos instrumentos internacionales (lex certa).

Como ya sabemos, la situación mejora bastante en el Estatuto de la Corte Penal Internacional, pero no sólo porque mejora la definición de los delitos, sino porque el Estatuto establece un orden jerárquico de fuentes en el artículo 21.

\section{El principio mulla poena sine lege}

Mientras el principio nullum crimen sine lege ha experimentado una clara evolución en el derecho penal internacional, estando cada vez más cercano a la tradición de derecho codificado, pese a su mayor flexibilidad; con respecto al principio de legalidad de la pena también es posible evidenciar una evolución, pero un tanto menos significativa.

Los Tribunales de Núremberg y Tokio tuvieron amplia libertad para determinar las penas que aplicaron, incluida la pena de muerte ${ }^{34}$. Los Tribunales para la ex Yugoslavia y Ruanda pueden únicamente aplicar penas de prisión. En cuanto a la determinación de la pena, los Estatutos no contienen una pena específica para cada delito, sino sólo criterios, tales como la gravedad del ilícito, las circunstancias personales del condenado y las normas aplicables por los tribunales de la ex Yugoslavia y Ruanda (artículos 24 y 23 de los respectivos Estatutos). La Corte Penal Internacional recoge en el artículo 78 del Estatuto únicamente criterios generales, aplazándose la discusión para el momento de adoptar las Reglas de Procedimiento y Prueba. La Regla 145 es la que finalmente estableció criterios más específicos, conteniendo factores neutros, atenuantes y agravantes, ninguno de los cuales es taxativo. Pese a que el artículo 23 del Estatuto se titula Nulla poena sine lege, sólo se limita a señalar que el condenado será penado de conformidad con el Estatuto. Bastante más regulada se encuentra la ejecución de la pena que su misma determinación. Con todo, se establecieron al menos límites máximos de 30 años, siendo la prisión perpetua de carácter excepcional y revisable, de conformidad a los artículos 77 y 110 del Estatuto.

Tampoco las convenciones internacionales que establecen los delitos internacionales imponen pena alguna, como es el caso de las convenciones contra el Genocidio y las de Ginebra de 1949, que solamente caracterizan estos delitos como punibles. Evidentemente, tampoco hay penas específicas tratándose de los delitos consuetudinarios como los crímenes contra la humanidad ${ }^{35}$.

Por lo visto, es forzoso concluir que en la realidad penal internacional, la legalidad de la pena es bastante reducida, contentándose con estigmatizar la conducta como punible, fijando ciertos límites en cuanto al tipo de penas y topes máximos de privación de libertad y los criterios de determinación de la pena, que en general no son taxativos. Por ello, la doctrina penal, de nuestra tradición jurídica, ha sido en general bastante crítica sobre las insuficiencias de la legalidad de la pena en el Estatuto de Roma (Álvarez García, 2009: 41 y ss.).

Sin embargo, esto no debe inducirnos a confusión y considerar que se trata de delitos sin pena, ya que, como bien dijera hace mucho Quintano Ripollés, la sanción existe, siendo el quantum lo que se ignora, y ello de alguna manera entra en el juego de aplicación judicial de las penas (1955: 105).

\footnotetext{
${ }^{34}$ El artículo 27 del Estatuto del Tribunal de Núremberg disponía: "En caso de dictar una sentencia condenatoria, el Tribunal podrá imponer la pena de muerte o la que estime conveniente y justa".

${ }^{35}$ Con todo, se ha elaborado, de manera privada, un proyecto de Convención sobre Crímenes de Lesa Humanidad (para mayores detalles, véase Ambos, 2012: 1-30).
} 
Pero, ¿satisface esto el principio de legalidad de la pena en su dimensión como derecho humano?

Tanto el artículo 15 del Pacto Internacional como el artículo 7 del Convenio Europeo establecen que, o bien que el delincuente se beneficiará de una ley que disponga de una pena más leve, o bien que no se puede imponer una pena más grave que la aplicable en el momento en que la infracción fue cometida. Ambas redacciones, como se puede apreciar, nos revelan la existencia de una ley o norma que de alguna manera establece un cierto margen punitivo limitado, a fin de poder comparar si la nueva norma establece una pena más o menos grave y así poder evaluar la retroactividad in bonam partem o si debemos atenernos a la prohibición de la retroactividad in malam partem.

Frente a este escenario una alternativa es simplemente constatar que la realidad actual, en cuanto al principio de legalidad de la pena, no cumple con las convenciones internacionales de derechos humanos. La otra alternativa, es la de Antonio Cassese, quien reconoce que, pese a algunas limitaciones en cuanto a la discrecionalidad de los Tribunales "este principio no es aplicable a nivel internacional, donde la tarifación de la pena no existe" (2008: 51-52).

\section{Conclusiones}

Admitido el hecho de que el derecho penal internacional debe someterse al principio de legalidad, en la conjugación entre derecho internacional y derecho penal, así como entre el common law y el civil law, el principio de legalidad internacional ha sido entendido como nullum crimen sine iure, estableciéndose más bien un estándar de mínimos, de juridicidad más que de legalidad estricta, expresado en los conceptos de previsibilidad y accesibilidad.

Este estándar ha sido fijado por el Tribunal Europeo de Derechos Humanos, lo que significaría que si nos adecuamos a él, en principio no se violarán los derechos del acusado.

La propia gravedad de los crímenes y el hecho de que los delitos internacionales se basan en delitos comunes subyacentes, como homicidios, secuestros, torturas, etc., que son punibles en todos o casi todos los ordenamientos internos, reduce considerablemente los riesgos de arbitrariedad frente a un principio de juridicidad mínimo.

Si admitimos que estos crímenes internacionales son ius cogens, la discusión en cuanto a las fuentes formales del derecho penal internacional disminuye en importancia, ya que no se trata delitos que surjan de manera repentina, como puede ocurrir en el ámbito interno, sino que son bastante bien conocidos y reconocidos en todo el mundo, y son básicamente los mismos delitos de Núremberg, de los Principios de Núremberg, del proyecto de Código de Crímenes contra la Paz y Seguridad de la Humanidad, de los Estatutos de los Tribunales de la ex Yugoslavia, Ruanda, y finalmente de la Corte Penal Internacional -cuyo Estatuto en este último caso ha debido ser ratificado por los Estados parte.

Por ello, no parece afortunada la expresión "derecho no escrito" para hacer referencia al derecho consuetudinario y a los principios generales, como si fueran normas que estuvieran flotando en el aire o fueran concebidas en la mente del juez y materializadas de improviso en una sentencia. Un verdadero derecho "no escrito" no satisface en ningún caso los estándares de "accesibilidad" primero (pues no habría cómo acceder a él), y "previsibilidad" después. Esto es válido no sólo para el derecho penal internacional, sino que incluso puede afirmarse con respecto al 
common law, donde el juez se basa siempre en un derecho escrito para dictar sentencia: sea una "Act" (statutory offences) o un precedente, una sentencia previa, también escrita (common law offence). Los crímenes internacionales están contenidos en documentos escritos, bien conocidos. Lo que sucede es que en la actualidad se plantea su aplicación universal, y la forma de hacerlo es mediante el derecho consuetudinario, los principios o el ius cogens. Pero hablar de derecho no escrito, pareciera ser una impropiedad de lenguaje.

Con respecto al nullum crimen sine poena también existe una evolución, pero de menor significación, que difícilmente puede estimarse como satisfactoria, no sólo desde el civil law, sino desde las propias convenciones de derechos humanos. Corresponderá a los Tribunales internacionales, particularmente a la Corte Penal Internacional, fijar estándares que le permitan una mayor concreción.

Bibliografía

Jurisprudencia, informes y resoluciones de Organismos Internacionales

CORTE INTERAMERICANA DE DERECHOS HUMANOS (1999), Caso Castillo Petruzzi y otros Vs. Perú (Fondo, Reparaciones y Costas).

CORTE INTERAMERICANA DE DERECHOS HUMANOS (2001), Caso Baena Ricardo y otros Vs. Panamá (Fondo, Reparaciones y Costas).

CORTE INTERAMERICANA DE DERECHOS HUMANOS (2004a), Caso Ricardo Canese Vs. Paraguay (Fondo, Reparaciones y Costas).

CORTE INTERAMERICANA DE DERECHOS HUMANOS (2004b), Caso Lori Berenson Mejía Vs. Perú (Fondo, Reparaciones y Costas).

CORTE PERMANENTE DE JUSTICIA INTERNACIONAL (CPJI) (1935), Opinión Consultiva, Consistencia de Ciertos Decretos Legislativos con la Constitución de la Ciudad Libre de Danzing, Series A/B N65, disponible en la siguiente dirección electrónica: http://www.icj-cij.org/pcij/serie AB/AB 65/01 Decretslois dantzikois Avis consultatif.pdf (fecha de consulta: 11 de septiembre de 2016).

PREPARATORY WORK ON ARTICLE 7 OF THE EUROPEAN CONVENTION OF HUMAN RIGTHS (1957), Information document prepared by the Secretariat of the Comission, disponible en la siguiente dirección electrónica: http://www.echr.coe.int/LibraryDocs/Travaux/ECHRTravaux-ART7-DH(57)6BIL1674978.pdf (fecha de consulta: 11 de septiembre de 2016).

PREPARATORY WORK ON ARTICLE 7 OF THE EUROPEAN CONVENTION OF HUMAN RIGTHS (19070), Information prepared by the Registry, disponible en la siguiente dirección electrónica: http://www.echr.coe.int/LibraryDocs/Travaux/ECHRTravaux-ART7CDH(70)10-BIL1338890.pdf (fecha de consulta: 11 de septiembre de 2016).

REPORT OF THE SECRETARY-GENERAL PURSUANT TO PARAGRAPH 2 OF SECURITY COUNCIL RESOLUTION 808 (1993), S/25704, disponible en la siguiente dirección electrónica: http://www.icty.org/x/file/Legal\%20Library/Statute/statute re808 1993 en.pdf (fecha de consulta: 12 de septiembre de2016).

TRABAJOS PREPARATORIOS DEL CONVENIO EUROPEO DE DERECHOS HUMANOS, disponible en la siguiente dirección electrónica: http://www.echr.coe.int/Documents/Library TravPrep Table ENG.pdf (fecha de consulta: 11 de septiembre de 2016).

TRIBUNAL EUROPEO DE DERECHOS HUMANOS (1995a), Caso G. contra Francia, $\mathrm{N}^{\circ} 15312 / 89$. 
TRIBUNAL EUROPEO DE DERECHOS HUMANOS (1995b), Caso S.W. contra el Reino Unido, № 20166/92.

TRIBUNAL EUROPEO DE DERECHOS HUMANOS (1995c), Caso C.R. contra el Reino Unido, № 20190/92.

TRIBUNAL EUROPEO DE DERECHOS HUMANOS (1996), Caso Cantoni contra Francia, N $N^{\circ} 17862 / 91$.

TRIBUNAL EUROPEO DE DERECHOS HUMANOS (1999), Caso Başkaya y Okçouglu contra Turquía, Nos 23536/94 y 24408/94.

TRIBUNAL EUROPEO DE DERECHOS HUMANOS (2000), Caso Coëme y otros contra Bélgica, Nos 32492/96, 32547/96, 32548/96, 33209/96 y 33210/96.

TRIBUNAL EUROPEO DE DERECHOS HUMANOS (2001a), Caso Streletz, Kessler y Krenz contra Alemania, Nos 34044/96, 35532/97 y 44801/98.

TRIBUNAL EUROPEO DE DERECHOS HUMANOS (2001b), Caso K.-H.W contra Alemania, № 37201/97.

TRIBUNAL EUROPEO DE DERECHOS HUMANOS (2002a), Caso E. K. contra Turquía, N² 28496/95

TRIBUNAL EUROPEO DE DERECHOS HUMANOS (2002b), Caso Tess contra Letonia (dec.), $\mathrm{N}^{\circ} 34854 / 02$.

TRIBUNAL EUROPEO DE DERECHOS HUMANOS (2006), Caso Achour contra Francia, $\mathrm{N}^{\circ} 67335 / 01$.

TRIBUNAL EUROPEO DE DERECHOS HUMANOS (2007), Caso Jorgic contra Alemania, № 74613/01.

TRIBUNAL EUROPEO DE DERECHOS HUMANOS (2008), Caso Korbely contra Hungría, N ${ }^{\circ}$ 9174/02.

TRIBUNAL EUROPEO DE DERECHOS HUMANOS (2009), Caso Scoppola contra Italia $\left(n^{\circ} 2\right), \mathrm{N}^{\circ} 10249 / 03$.

TRIBUNAL EUROPEO DE DERECHOS HUMANOS (2010), Caso Kononov contra Letonia, N ${ }^{\circ} 36376 / 04$.

TRIBUNAL EUROPEO DE DERECHOS HUMANOS (2012), Caso Del Río Prada contra España, No 42750/09.

TRIBUNAL EUROPEO DE DERECHOS HUMANOS (2013a), Caso Vyerentsov contra Ukraine, $N^{\circ} 20372 / 11$.

TRIBUNAL EUROPEO DE DERECHOS HUMANOS (2013b), Caso Maktouf y Damjanović contra Bosnia y Herzegovina, Nos 2312/08 y 34179/08.

Monografías, artículos y contribuciones a obras colectivas

ÁLVAREZ GARCÍA, F. (2009), Sobre el Principio de legalidad, Tirant Lo Blanch, Valencia.

AMBOS, K. (2012), "Crímenes de lesa humanidad y la Corte Penal Internacional", Revista General de Derecho Penal, lustel, núm. 17, pp. 1-30.

AMBOS, K. (1996), "Establishing an International Criminal Court and an International Criminal Code", European Journal of International Law, Vol.7, núm. 4, pp. $519-544$.

AMBOS, K. (2006), La Parte General del Derecho Penal Internacional, Bases para una elaboración dogmática, Temis, Konrad-Adenauer, Bogotá.

CASADEVALL, J. (2012), El Convenio Europeo de Derechos Humanos, el Tribunal de Estrasburgo y su Jurisprudencia, Tirant Lo Blanch, Valencia.

CASSESE A. (2008), International Criminal Law, $2^{\text {a }}$ ed., Oxford University Press, New York.

CEREZO MIR, J. (2004), Curso de Derecho Penal Español, Parte General, Tecnos, Madrid.

CHERIF BASSIOUNI, M. (1996), The Law of International Criminal Tribunal For The Former Yugoslavia, Transnational Publishers, New York. 
DE VICENTE MARTíneZ, R. (2004), El Principio de Legalidad Penal, Tirant Lo Blanch, Valencia.

DIEZ-PICAZO, L. (2008), Sistema de Derechos Fundamentales, Thomson/Civitas, Aranzadi, Pamplona.

ESPEJO YAKSIC, N., LEIVA GARCÍA, C. (2012), Digesto de jurisprudencia de la corte Interamericana de Derechos Humanos (Enero de 1984 - Febrero de 2012), Abeledo Perrot y Thomson Reuters, Santiago de Chile.

FERDINANDUSSE, W. (2006), Direct Application of International Criminal Law in National Courts, TMC Press, The Hague.

GALLANT, K. (2012), "La legalidad como norma del derecho consuetudinario internacional: la retroactividad de los delitos y de las penas". En: MONTIEL, J.P. (ed.), La crisis del principio de legalidad en el nuevo derecho penal: ¿decadencia o evolución?, Madrid / Barcelona / Buenos Aires / Sao Paulo, Marcial Pons, pp. 315-354.

GALLANT, K. (2009), The Principle of Legality in International and Comparative Criminal Law, Cambridge University Press, Cambridge.

GIL GIL, A. (1999), Derecho penal internacional. Especial consideración del delito de Genocidio, Tecnos, Madrid.

HARRIS, D., O'BOYLE, M., BATES, E., BUCKLEY, C., HARVEY, P., LAFFERTY, M., CUMPER, P., ARAI, Y. y GREEN, H. (2009), Harris, O'Boyle \& Warbrick. Law of the European Convention on Human Rights, Oxford University Press, Oxford.

HASSEMER, W. (1995), Crítica al Derecho penal de hoy, Ad-Hoc, Buenos Aires.

HORMAZABAL MALARÉE, H. (2013), "Crímenes internacionales, jurisdicción y principio de legalidad penal". En: REBOLLO VARGAS, R. y TENORIO TAGLE, F. (dirs.), Derecho Penal, Constitución y Derechos, Barcelona, Bosch, pp. 253-280.

HUERTA TOCILDO, S. (1993) "El derecho fundamental a la legalidad penal", Revista española de derecho constitucional, núm. 39, pp. 81-113.

HUERTA TOCILDO, S. (2009) "El Contenido debilitado del principio europeo de legalidad penal". En: GARCÍA ROCA, J., SANTOLAYA, P. (coords.), La Europa de los Derechos. El Convenio Europeo de Derechos Humanos, Madrid, Centro de Estudios Políticos y Constitucionales, pp. 511-543.

JAKOBS, G. (1997), Derecho Penal. Parte General. Fundamentos y Teoría de la Imputación, Marcial Pons, Madrid.

JIMÉNEZ DE ASÚA, L. (1950), Tratado de derecho penal, Losada, Buenos Aires.

JIMÉNEZ DE ASÚA, L. (1964), Tratado de Derecho Penal, Losada, Buenos Aires.

KELSEN, H. (2008), La paz por medio del derecho, Trotta, Madrid.

LAMARCA PÉREZ, C. (2011), Voz: "Principio de legalidad Penal", Eunomia. Revista en Cultura de la legalidad, núm. 1, pp. 156-160.

MARIÑO MENÉNDEZ, F. (2005), Derecho Internacional Público, Parte General, Trotta, Madrid.

MIR PUIG, S. (2008), Derecho Penal, Parte General, Reppertor, Barcelona.

MUÑoz CONDE, F. y GARCíA ARÁN, M. (2010), Derecho Penal, Parte General, Tirant Lo Blanch, Valencia.

NILSSON, J. (2007), "The principle nullum crimen sine lege". En: OLUSANYA, O., Rethinking International Criminal Law: The Sustantive Part, Groningen, Europa Law Publishing, pp. 35-64.

OLÁSOLO, H. (2013), "El principio nullum crimen sine iure en el derecho internacional contemporáneo", Anuario Iberoamericano de derecho internacional penal, Vol. I, pp. 18-42.

OLLÉ SESÉ, M. (2008), "EI Principio de legalidad en el Derecho penal internacional: su aplicación por los tribunales domésticos". En: GARCÍA VALDÉS, C., CUERDA RIEZU, A., MARTÍNEZ ESCAMILLA, M. ALCÁCER GUIRAO, R. y 
VALLE MARISCAL DE GANTE, M. (coords.), Estudios Penales en homenaje a Enrique Gimbernat. Madrid, Edisofer, pp. 559-582.

PASTOR, D. (2006), El poder penal internacional, una aproximación jurídica crítica a los fundamentos del Estatuto de Roma, Atelier, Barcelona.

QUINTANO RIPOLLÉS, A. (1955), Tratado de Derecho Penal Internacional e Internacional Penal, Consejo Superior de Investigaciones Científicas, Instituto francisco de Vitoria, Madrid.

QUINTERO OLIVARES, G. (2010), Parte General del Derecho Penal, Aranzadi, Navarra.

REMIRO BROTONS, A. (1999), El caso Pinochet: los límites de la impunidad, Biblioteca Nueva, Madrid.

SARMIENTO, D., MIERES, L., PRESNO, M. (2007), Las sentencias básicas del Tribunal Europeo de Derechos Humanos, Aranzadi, Pamplona.

SCHABAS, W. (ed.) (2013), The Universal Declaration of Human Rights. The Travaux Préparatoires, Cambridge University Press, New York.

SCHMITT, C. (2006), El crimen de guerra de agresión en el derecho internacional y el principio «nullum crimen, nulla poena sine lege», Hamurabi, Buenos Aires.

TRAHAN, J. (2010), Genocide, War Crimes and Crimes Against Humanity: A Digest of the Case Law of the International Criminal Tribunal for Rwanda, Human Rights Watch, New York.

VAN DIJK, P., VAN HOOF, F., VAN ROJIN, A., ZWAAK, L. (edts.) (2006), Theory and Practice of the European Convention on Human Rights, Intersentia, Antwerpen / Oxford.

WERLE, G. (2005), Tratado de Derecho Penal Internacional, Tirant Lo Blanch, Valencia. 